\section{Kidney \\ Blood Pressure \\ Research}

Kidney Blood Press Res 2014;39:154-163

DOI: 10.1159/000355791

Published onlıne: July 29, 2014

(C) 2014 S. Karger AG, Basel

www.karger.com/kbr

Accepted: April 11, 2014

1423-0143/14/0393-0154\$39.50/0

This is an Open Access article licensed under the terms of the Creative Commons AttributionNonCommercial 3.0 Unported license (CC BY-NC) (www.karger.com/OA-license), applicable to the online version of the article only. Distribution permitted for non-commercial purposes only.

Review

\title{
Physical Activity in Chronic Kidney Disease: a Plausible Approach to Vascular Calcification?
}

\author{
Carlo Basile Carlo Lomonte $^{\mathrm{a}}$ Piero Lisia Cristina Karohl $^{\mathrm{b}}$ Biagio Di Iorio ${ }^{c}$ \\ Antonio Bellasid
}

aDivision of Nephrology, Miulli General Hospital, Acquaviva delle Fonti (BA), Italy; bivision of Nephrology, Hospital de Clinicas de Porto Alegre, Universidade Federal do Rio Grande do Sul, Porto Alegre, RS, Brazil; 'Division of Nephrology, "A Landolfi" Hospital, Solofra (AV); 'Division of Nephrology, Sant' Anna Hospital, Como, Italy

\section{Key Words}

Vascular calcification • Chronic kidney disease • Lifestyle modification • Physical activity

\begin{abstract}
Vascular calcification (VC) is a prominent feature that affects up to 40 to $80 \%$ of Chronic Kidney Disease (CKD) patients depending on the degree of renal impairment. Though etiology and pathogenesis of the different types of VC are far from being elucidated, it is conceivable that an imbalance between promoters and inhibitors represents the condition that triggers VC deposition and progression. In addition to traditional cardiovascular risk factors, several lines of evidence suggest that specific factors may affect the arterial system and prognosis in CKD. Over the last decade, a few pharmacological strategies aimed at controlling different selected risk factors for $\mathrm{VC}$ have been investigated yielding conflicting results. In light of the complicated interplay between inhibitors and promoters as well as the fact that VC represents the result of cumulative and prolonged exposure to multiple risk factors, a more comprehensive risk modification approach such as lifestyle modification or physical activity (PA) may represent a valid strategy to attenuate VC deposition and progression.

We herein aim at reviewing the rationale and current evidence on the potential for lifestyle modification with a specific focus on PA as a cost-effective strategy for VC treatment.
\end{abstract}

Copyright $(2014$ S. Karger AG, Basel

\section{Introduction}

The cardiovascular (CV) risk of patients suffering from Chronic Kidney Disease (CKD) is few folds higher than that of the general population and it progressively increases with 


\section{Kidney Blood Pressure Research}

\begin{tabular}{l|l}
\hline DOI: $10.1159 / 000355791$ & C 2014 S. Karger AG, Basel
\end{tabular}

Published onlıne: July 29, 2014

www.karger.com/kbr

Basile et al.: Vascular Calcification and Physical Activity

the degree of renal function impairment [1]. Of note, traditional risk factors only partially account for such extreme risk and numerous epidemiological and observational studies have identified other CKD specific factors that may contribute to the disproportionate CV risk observed as renal function declines.

Among other factors, cardiovascular calcifications (CCV) represent a valid marker and a potential promoter of vascular damage [2-4]. Indeed, longitudinal studies have repeatedly documented that presence and extension of CCV are both associated with adverse outcome in the general population as well as CKD patients [5-7].

A convincing body of evidence suggests that CCV is a prominent feature of vascular disease in CKD patients with up to $80 \%$ of patients receiving chronic dialysis exhibiting a certain degree of vascular calcification (VC) [8]. In the last decades, the natural history of $\mathrm{VC}$ received a large degree of attention and even though the pathogenesis of different types of vascular and valvular calcification are far from being conclusively established, it is conceivable that a prolonged imbalance between promoters and inhibitors of VC represents the condition that triggers VC deposition and progression [9]. Indeed, contrary to a circulating factor that fluctuates according to the instantaneous risk at which an individual is exposed in a specific timeframe, a tissue marker of CV damage such as CCV likely reflects the end result of the cumulative exposure to numerous factors during a prolonged exposure [4].

We herein aim at summarizing the rationale and current evidence on the potential for lifestyle modification with a specific focus on physical activity (PA) as a cost-effective strategy for VC treatment. Details on how the medical literature search was performed are provided in Table 1. A list of abbreviations used in the text is provided in Table 2.

Table 1. Literature search methodology adopted for this review article

\begin{tabular}{|c|c|}
\hline Sources & PubMed (http://www.ncbi.nlm.nih.gov/pubmed) \\
\hline Data search & November 2013-January 2014 \\
\hline Filters & No filter \\
\hline \multicolumn{2}{|l|}{ Key words: } \\
\hline Coronary artery calcification & $\begin{array}{l}\text { coronary artery calcification[Title/Abstract] OR CAC[Title/Abstract] OR } \\
\text { coronary artery calcium[Title/Abstract] OR coronary } \\
\text { calcification[Title/Abstract] OR calcification[Title/Abstract] OR coronary } \\
\text { arterial calcification[Title/Abstract] OR arterial calcification[Title/Abstract] } \\
\text { OR calcium score[Title/Abstract] OR coronary computed tomographic } \\
\text { angiography [Title/Abstract] OR CCTA [Title/Abstract] OR vascular } \\
\text { calcification [Title/Abstract] }\end{array}$ \\
\hline Cardio-Vascular calcification & $\begin{array}{l}\text { Vascular calcification[Title/Abstract] OR arterial calcification } \\
\text { [Title/Abstract] OR heart calcification [Title/Abstract] OR valvular } \\
\text { calcification[Title/Abstract] OR calcification[Title/Abstract] OR aorta } \\
\text { calcification [Title/Abstract] OR large artery calcification[Title/Abstract] OR } \\
\text { calcium score [Title/Abstract] OR abdominal calcification [Title/Abstract] } \\
\text { OR [Title/Abstract] OR vessel calcification [Title/Abstract] }\end{array}$ \\
\hline Physical Activity & $\begin{array}{l}\text { Physical activity [Title/Abstract] OR Physical exercise [Title/Abstract] OR } \\
\text { Physical fitness [Title/Abstract] OR Physical performance [Title/Abstract] } \\
\text { OR exercise training [Title/Abstract] OR aerobic exercise [Title/Abstract] } \\
\text { OR resistance exercise [Title/Abstract] OR exercise performance } \\
\text { [Title/Abstract] OR cardiopulmonary exercise [Title/Abstract] }\end{array}$ \\
\hline Chronic Kidney Disease & $\begin{array}{l}\text { chronic kidney disease [Title/Abstract] OR kidney disease [Title/Abstract] } \\
\text { OR chronic renal disease [Title/Abstract] OR renal disease [Title/Abstract] } \\
\text { OR chronic renal insufficiency [Title/Abstract] OR renal insufficiency } \\
\text { [Title/Abstract] OR chronic renal impairment [Title/Abstract] OR renal } \\
\text { impairment [Title/Abstract] OR dialysis [Title/Abstract] OR chronic dialysis } \\
\text { [Title/Abstract] OR maintenance dialysis [Title/Abstract] OR chronic } \\
\text { hemodialysis [Title/Abstract] OR maintenance hemodialysis } \\
\text { [Title/Abstract] OR chronic peritoneal dialysis [Title/Abstract] OR } \\
\text { maintenance peritoneal dialysis [Title/Abstract] OR hemodialysis } \\
\text { [Title/Abstract] OR peritoneal dialysis [Title/Abstract] OR CKD } \\
\text { [Title/Abstract] OR HD [Title/Abstract] OR PD [Title/Abstract] }\end{array}$ \\
\hline
\end{tabular}




\section{Kidney Blood Pressure Research}

\section{Localization and risk factors of VC}

In spite of a profuse effort on understanding VC pathogenesis, only a few studies with limited samples have attempted to characterize where VC are localized within the arterial wall and whether different types of VC localization are due to specific risk factors or portend different risk of CV event. Furthermore, a lack of a reliable diagnostic tool that allows for an accurate discrimination among different forms of CCV further complicates the scenario [10]. In a relatively large series of 202 hemodialysis patients on maintenance dialysis, London and coworkers described two types of VC within the arterial wall [11]. The first type of VC is located within the intimal layer of the arterial
Table 2. List of abbreviations used in the text

\begin{tabular}{ll}
\hline & \\
\hline CAC & Coronary artery calcification \\
CI & Confidence interval \\
cIMT & Carotid intima media thickness \\
CKD & Chronic Kidney Disease \\
CV & Cardiovascular \\
CCV & Cardiovascular calcification \\
CVD & Cardiovascular disease \\
EE & exercise-related energy expenditure \\
eGFR & Estimated glomerular filtration rate \\
ESRD & End-stage renal disease \\
HRT & Hormone replacement therapy \\
OR & Odds ratio \\
PA & Physical activity \\
VC & Vascular calcification \\
\hline
\end{tabular}

wall and is likely related to the atherosclerotic burden and traditional risk factors such as diabetes, smoking, dyslipidemia [11]. To the contrary, the second type of VC is located within the medial layer of arterial wall and is linked to factors such as mineral metabolism and uremia-related toxins [11]. Though the majority of available studies [12-16] suggest that the medial calcification may be the predominant type of VC in CKD patients, not all records seem to corroborate this notion. A recent cross-sectional, case-control study of 232 patients on chronic dialysis and 208 age- and sex- matched controls concluded that VC in large conduit arteries is predominantly located in the intima of the arteries and likely connected with atherosclerosis, traditional CV risk factors and inflammation [17].

Regardless of the pathogenetic pathways and location of $\mathrm{VC}$, a strong and graded association of $\mathrm{VC}$ and decline in renal function [18], microalbuminuria [19] as well as increased risk of CV and all-cause mortality is documented [5, 11, 20-22]. Of importance, whether these associations are causative or merely reflect an accelerated senescence of the CV system, remains to be established. In a large cohort of 1,703 subjects with history of coronary artery disease but not renal impairment, the association between the estimated glomerular filtration rate (eGFR) was attenuated in younger individuals suggesting that age may be a key factor that modulates these associations [22]. Nevertheless, a convincing body of evidence suggests that end-stage renal disease (ESRD) and dialysis are two potent promoters of cardiovascular disease (CVD) and VC deposition and progression [23, 24].

Though further work is needed to elucidate the mechanisms that trigger VC, a few attempts at reducing the risk of VC and CVD through lifestyle interventions have been tested. Numerous observations support the notion that PA may protect against CVD $[25,26]$. A lower mortality and a better CV risk profile (i.e. better control of dyslipidemia, hypertension, diabetes and obesity, inflammation) have been shown in physically active individuals [2527]. However, the impact of PA on markers of subclinical CV disease such as VC remains controversial $[26,28-31]$ and it is unclear whether these conflicting results are due to the observed heterogeneity of different methodologies and study designs adopted or due to the level of PA investigated. Furthermore, PA is usually part of a lifestyle modification program enforced for CVD prevention and is often coupled with the use of drugs with anti-atherogenic properties. All these factors complicate the interpretation of available data.

\section{PA and markers of subclinical atherosclerosis in the general population}

The large majority of available data is cross-sectional or observational in nature and has investigated the relationship between PA and different markers of subclinical atherosclerosis [usually coronary artery calcification (CAC) or carotid intima media thickness (cIMT)] over 


\section{Kidney Blood Pressure Research}

a relatively short period of time making comparisons among studies complicated, thus preventing from definitive conclusions on the causal effect of PA on VC.

In a large cohort of 779 asymptomatic high-risk (with at least 2 traditional CV risk factors) individuals of both genders referred for electron beam computed tomography and CAC evaluation, Desai and coworkers [32] documented a graded cross-sectional association between PA intensity and CAC extension. The observed median CAC scores according to level of PA were 24, 18, and 11 (p-trend < 0.002) among individuals reporting a sedentary lifestyle (no PA), or being engaged in moderate-duration ( $<30$ minutes 1 to 2 times/week) or long-duration ( $\geq 30$ minutes $\geq 3$ times/week) PA, respectively [32]. Notably, the inverse and independent association between PA and CAC was confirmed after multivariable adjustments.

A similar conclusion was reached when male participants from the Prospective Army Coronary Calcium Project ( $\mathrm{n}=1637$, mean age 42.8 years; no history of coronary heart disease) were studied. Men with CAC were more likely to be dyslipidemic and sedentary. Progressive adjustment for confounders showed that only non-HDL cholesterol (odds ratio [OR] 1.012 per mg/dL; 95\% Confidence Interval [CI] 1.002 - 1.023; $\mathrm{P}=.019$ ), age (OR 1.119 per year; 95\% CI 1.063 - 1.178; P <.001) and PA (OR 0.808; 95\% CI $0.703-0.928 ; \mathrm{P}=0.003$ ) were associated with the presence of CAC [33].

Some albeit not all longitudinal studies also suggest that PA and cardio-respiratory fitness portend a lower risk of developing VC. Among the 2,373 African-American and white young adults enrolled in the Coronary Artery Risk Development in Young Adults Study, baseline cardio-respiratory fitness was inversely related with the development of CAC during the subsequent 15 years of follow-up. Nonetheless, whether the main determinant of CAC deposition is the genetic background or PA of study subjects could not be addressed in the study [34].

Conversely, a recent study that investigated the association between CAC and PA longitudinally over a prolonged follow-up (i.e. 25-year observation) [31], failed to documenta linear association between PA level and CAC [30]. However, among the 101 middle-aged men recruited in the survey, those who maintained a low-to-moderate PA [exercise-related energy expenditure (EE) in kcal/week at baseline < 2050] exhibited the largest CAC burden when compared to individuals who regularly maintained a higher degree of PA (EE in kcal/week at baseline $>2050$ ) [31]. A similar pattern was noticed when other measures of subclinical atherosclerosis were considered [namely: cIMT and reactive hyperemia index], suggesting that a regular PA with EE above $2050 \mathrm{Kcal} /$ week may attenuate CV senescence [31]. Notably, in this specific cohort of individuals the lowest risk of atherosclerosis was observed in the group with stable intermediate PA level (2050 - $3840 \mathrm{kcal} /$ week) and further increase in PA did not provide additional protection against atherosclerosis development [31].

What is the optimal level of PA to prevent CVD and CCV is still matter of debate. In a small series of 13 highly active endurance-trained athletes and 12 sedentary men and women of 60 to 78 years of age, authors could not detect any difference in CAC according to level of PA [35]. However, when men (7 athletes and 6 sedentary males) were examined separately, a significant correlation between PA, CAC and maximal oxygen consumption was noted, suggesting that chronic vigorous exercise may protect against CAC at least in men [35]. In a larger and more powered study of 8,565 middle-aged men, Sung and coworkers [36] detected a significant increase in CAC prevalence and extension among those individuals who exercised more frequently (more than three times per week) [36]. Whether these unexpected findings are due to a potential harm of intense PA or due to a confounding by indication is unclear at the current time. Indeed, subjects at higher CV risk (i.e. diabetic or hypertensive patients) with higher degree of CAC are advised to exercise more frequently than peers at low CV risk. However, some concern regarding extreme PA exists. Goel and coworkers [37] reported on a case of a marathon runner with accelerated CAC progression possibly due to the oxidative stress promoted by this arduous aerobic activity [37]. In line with this hypothesis, the investigators of the Heinz Nixdorf Recall Study [38, 39] showed that 108 apparently healthy marathon runners (older than 50 years) presented a similar 


\section{Kidney Blood Pressure Research}

CAC distribution of age-matched controls (median CAC: 36 vs 38 Agatston Units, $\mathrm{p}=0.36$, respectively) but greater CAC burden than peers matched by the Framingham risk score (median CAC: 36 vs 12 Agatston Units, $\mathrm{p}=0.02$, respectively) [38]. Of importance, the eventfree survival was inversely related to CAC burden during a mean follow-up of $21.3 \pm 2.8$ months [38], suggesting that CAC portends a poor prognosis and is an early indicator for subclinical cardiac alteration even in this apparently super-healthy population [39-41].

In spite of a strong rationale, not all cross-sectional and observational studies document a significant association between PA and CAC or VC. Whether these findings are due to a certain degree of population, age or gender heterogeneity, difference in study samples and designs, or due to the relative inaccuracy of self-reported PA, or whether there is a PA threshold above which PA may be harmful, remains to be investigated in future ad hoc studies. Among 6,814 male and female participants of the Multi-Ethnic Study of Atherosclerosis [42], neither cIMT nor CAC were associated with any level of intensity of self-reported PA in either gender after adjustment for age, race/ethnicity, clinic site, education, income, and smoking [42]. Only walking pace was favorably associated with CAC and other markers of subclinical CVD [namely, cIMT, Ankle-Brachial index] with some differences between men and women [42]. Further adjustments for traditional CV risk factors such as dyslipidemia, blood pressure, diabetes, body mass index attenuated the statistical significance of these associations suggesting that the link between PA and CAC is modulated by traditional CV risk factors [42]. Similarly, Taylor and coworkers failed to confirm the association of PA and CAC at any level of physical exercise in a cohort of 630 consecutive asymptomatic 39 to 45 year old men and women. Notably, these findings were independent of a healthier CV risk profile, including lower body mass index and insulin resistance [30]. In another series of 443 healthy men and women (mean age $=66 \pm 6$ years), enrolled in the Whitehall II epidemiological cohort, authors did not observe any association between CAC and PA after adjustment for age, sex and traditional CV risk factors [43], suggesting that VC may not mediate the CV benefits associated with regular physical exercise.

Age may be a strong effect-modifier of the relationship between PAand CAC. von Bonsdorff et al [44] observed in a longitudinal cohort of 4,074 participants of the AGES-Reykjavik Study (mean age 76 years) that the extent of CAC and decreased physical performance are related and both independently predict mortality [44]. In contrast, in a cohort of 1,824 subjects older than 70 years enrolled in the Multi-Ethnic Study of Atherosclerosis no independent association between PA and cIMT or CAC was detected [45]. If a reduced PA is the cause or the effect of increased CAC or if the link between PA and CAC is confounded by the increased prevalence of sedentary lifestyle and CAC in the elderly remains to be elucidated.

PA assessment is another factor that may account for the conflicting results yielded by different studies. Measured and objectively assessed rather than self-reported PA was independently associated with a lower risk of a CAC greater than 100 Agatston Units (OR $0.62,95 \%$ CI $0.40-0.96$ ) and lower IMT (beta coefficient $=-0.04,95 \%$ CI -0.01 to $-0.07 \mathrm{~mm}$ ) in a cross-sectional study of 530 middle-aged (mean age 63 years) adults of both genders (50\% males) [46].

Finally, the role of sex hormones as a potential effect-modifier of the relationship between PA and VC is also controversial. In a large cross-sectional study of 544 postmenopausal women aged 50 to 80 years [47], the use of hormone replacement therapy (HRT) as well as PA were associated with a significant and independent lower prevalence and CAC burden. However, the high co-linearity of PA and HRT (women on HRT were 4-fold more likely to exercise, $p=0.03$ ] [47] complicates the interpretation of these results. Furthermore, age or years of menopause may also modify the link between PA and VC in postmenopausal women, as suggested by a pooled analysis by Storti et al [48]. Indeed, the inverse association between PA and CAC was apparent in old (mean age 73.9 years) but not young (mean age 56 years) postmenopausal women though, as speculated by authors, these findings are likely due to the lower prevalence of any detectable CAC in the younger age group [48]. A similar conclusion was reached by Inzitari et al who investigated the association between CAC and PA in 387 old community-dwellers (mean age 78 years) from the Cardiovascular 


\section{Kidney \\ Blood Pressure Research}

\begin{tabular}{l|l}
\hline DOI: $10.1159 / 000355791$ & C 2014 S. Karger AG, Basel \\
\hline
\end{tabular}

Published onlıne: July 29, 2014

www.karger.com/kbr

Basile et al.: Vascular Calcification and Physical Activity

Health Study [49]. Among old women a linear association between CAC and PA could be demonstrated independent of multivariable adjustment [49]. Finally, Straub and coworkers [50] described in a cohort of 276 healthy women aged 60 - 85 years that PA was associated with an increase in the androgen to cortisol ratio as well low interleukin 6 and less severe abdominal aorta calcification postulating that the anti-atherogenic properties of PA may be mediated by the inhibition of inflammation operated by androgens [50].

In summary, evidence on the link between PA and VC is far from being conclusive. It seems that regular PA may protect against CVD and VC occurrence in healthy individuals though some concern about extremely vigorous exercise may apply. Future interventional studies should clarify whether the beneficial effect of PA is modulated by age or other CV risk factors and whether the effect of PA is relevant in both men and women.

\section{PA and markers of subclinical atherosclerosis in CKD}

Data on PA and vascular function or markers of subclinical CV disease in CKD patients are scanty, mainly derived from dialysis cohorts and suffer from similar limitations that affect studies in the general population. Of note, to the best of our knowledge, no study has ever investigated the impact of PA on VC. Nevertheless, a few considerations about the potential for PA as a way for VC attenuation can be made.

As eGFR declines, pulmonary and exercise tolerance progressively decrease [51]. In a cohort of 38 adult volunteers, the degree of renal impairment was associated to a graded decrease in peak oxygen consumption percentage and submaximal exercise tolerance [52]. In larger study of 1,111 CKD patients recruited in the Chronic Renal Insufficiency Cohort both low PA and frailty (estimated via the Short Physical Performance Battery - a summary test of gait speed, chair raises and balance -) were connected to chronic renal dysfunction [53]. In light of the impact of PA on blood pressure, dyslipidemia, hypertension, diabetes and obesity as well as the strong association between all these factors and VC, CKD patients may be one of the most suitable populations for implementing PA [25, 26]. However, future studies should test if the relationship between PA and better CV risk profile is not confounded by the frailty status.

Though conducted on 50 patients only, a recent randomized controlled trial showed that aerobic exercise $(15$ minutes low-intensity exercise during the first 2 hours of dialysis for 2 months) improves dialysis efficacy [54]. Considering that the uremic milieu is a potent promoter of VC and CVD in CKD [55], increasing dialysis efficacy may protect against VC deposition. Preliminary data support this hypothesis. A first case report in 2006 documented a significant walking distance improvement in a 59 year old men on maintenance dialysis with a peripheral arterial disease of lower extremities enrolled in a home-based exercise training program [56]. In a recent prospective study of 35 patients (19 active group vs 16 control group) on chronic hemodialysis, the intervention of 40 min exercise training during each hemodialysis session for 3 months was associated with a significant improvement in the skeletal muscle mass, physical performance as well as indexes of arterial stiffness and blood pressure control [57]. A similar trend toward reduced arterial stiffness was also reported in another small study aimed at comparing a home-based $v s$ an intradialytic exercise training program [58].

In summary, no study has ever tested the impact of regular exercise on VC in CKD or dialysis patients, though the few available data suggest a potential for this intervention in patients with impaired renal function.

\section{Conclusion}

A growing number of study supports the concept that VC is a marker of arterial damage and is associated with an adverse prognosis in the general population as well as CKD patients. 


\section{Kidney \\ Blood Pressure Research}

Basile et al.: Vascular Calcification and Physical Activity

Similarly, a few lines of evidence suggest that regular PA is associated with an improvement of traditional CV risk factors such as blood pressure, dyslipidemia and insulin resistance. In light of the link of these factors with VC in the general population as well as in CKD patients, it is plausible that PA may attenuate VC deposition and progression.

However, the impact of PA on VC still needs to be elucidated before advising PA in CKD patients. PA is usually part of a lifestyle modification program, and future studies should determine the real effect of each recommendation (i.e. PA, nutrition etc) on VC and prognosis on both genders. Similarly, it is currently unclear whether the association between PA and CAC is confounded by factors such as age or other traditional CV risk factors and ad hoc randomized controlled trials are needed to prove the causal relationship between PA and CVD and the advisable "dose" of PA in CKD patients. Future efforts are then required to shed light on efficacy and safety of this potentially cost-effective therapeutic strategy for VC and CVD in CKD patients.

\section{Disclosure Statement}

The authors state that they do not have any conflicts and nothing to disclose.

\section{References}

1 Go AS, Chertow GM, Fan D, McCulloch CE, Hsu CY: Chronic kidney disease and the risks of death, cardiovascular events, and hospitalization. N Engl J Med 2004;351:1296-1305.

-2 Bellasi A, Ferramosca E, Ratti C, Block G, Raggi P: Cardiac valve calcification is a marker of vascular disease in prevalent hemodialysis patients. J Nephrol 2012;25:211-218.

3 Bellasi A, Raggi P: Diagnostic and prognostic value of coronary artery calcium screening. Curr Opin Cardiol 2005;20:375-380.

4 Bellasi A, Raggi P: Vascular calcification in chronic kidney disease: usefulness of a marker of vascular damage. J Nephrol 2011;24 Suppl 18:S11-15.

5 Shantouf RS, Budoff MJ, Ahmadi N, Ghaffari A, Flores F, Gopal A, Noori N, Jing J, Kovesdy CP, KalantarZadeh K: Total and individual coronary artery calcium scores as independent predictors of mortality in hemodialysis patients. Am J Nephrol 2010;31:419-425.

-6 Verbeke F, Van Biesen W, Honkanen E, Wikstrom B, Jensen PB, Krzesinski JM, Rasmussen M, Vanholder R, Rensma PL: Prognostic Value of Aortic Stiffness and Calcification for Cardiovascular Events and Mortality in Dialysis Patients: Outcome of the Calcification Outcome in Renal Disease (CORD) Study. Clin J Am Soc Nephrol 2010;6:153-156.

7 Bellasi A, Lacey C, Taylor AJ, Raggi P, Wilson PW, Budoff MJ, Vaccarino V, Shaw LJ: Comparison of prognostic usefulness of coronary artery calcium in men versus women (results from a meta- and pooled analysis estimating all-cause mortality and coronary heart disease death or myocardial infarction). Am J Cardiol 2007;100:409-414.

8 Raggi P, Boulay A, Chasan-Taber S, Amin N, Dillon M, Burke SK, Chertow GM: Cardiac calcification in adult hemodialysis patients. A link between end-stage renal disease and cardiovascular disease? J Am Coll Cardiol 2002;39:695-701.

-9 Raggi P, Giachelli C, Bellasi A: Interaction of vascular and bone disease in patients with normal renal function and patients undergoing dialysis. Nat Clin Pract Cardiovasc Med 2007;4:26-33.

-10 Bellasi A, Raggi P: Techniques and technologies to assess vascular calcification. Semin Dial 2007;20:129133.

-11 London GM, Guerin AP, Marchais SJ, Metivier F, Pannier B, Adda H: Arterial media calcification in end-stage renal disease: impact on all-cause and cardiovascular mortality. Nephrol Dial Transplant 2003;18:17311740. 


\section{Kidney \\ Blood Pressure Research}

Basile et al.: Vascular Calcification and Physical Activity

12 Filgueira A, Carvalho AB, Tomiyama C, Higa A, Rochitte CE, Santos RD, Canziani ME: Is coronary artery calcification associated with vertebral bone density in nondialyzed chronic kidney disease patients? Clin J Am Soc Nephrol 2011;6:1456-1462.

13 Ohya M, Otani H, Kimura K, Saika Y, Fujii R, Yukawa S, Shigematsu T: Improved assessment of aortic calcification in Japanese patients undergoing maintenance hemodialysis. Intern Med 2010;49:2071-2075.

14 Stavroulopoulos A, Porter CJ, Pointon K, Monaghan JM, Roe SD, Cassidy MJ: Evolution of coronary artery calcification in patients with chronic kidney disease Stages 3 and 4, with and without diabetes. Nephrol Dial Transplant 2011;26:2582-2589.

-15 Roman-Garcia P, Carrillo-Lopez N, Fernandez-Martin JL, Naves-Diaz M, Ruiz-Torres MP, Cannata-Andia JB: High phosphorus diet induces vascular calcification, a related decrease in bone mass and changes in the aortic gene expression. Bone 2010;46:121-128.

16 Tamei N, Ogawa T, Ishida H, Ando Y, Nitta K: Serum fibroblast growth factor-23 levels and progression of aortic arch calcification in non-diabetic patients on chronic hemodialysis. J Atheroscler Thromb 2011;18:217-223.

-17 Coll B, Betriu A, Martinez-Alonso M, Amoedo ML, Arcidiacono MV, Borras M, Valdivielso JM, Fernandez E: Large artery calcification on dialysis patients is located in the intima and related to atherosclerosis. Clin J Am Soc Nephrol 2011;6:303-310.

18 Roy SK, Cespedes A, Li D, Choi TY, Budoff MJ: Mild and moderate pre-dialysis chronic kidney disease is associated with increased coronary artery calcium. Vasc Health Risk Manag 2011;7:719-724.

19 DeFilippis AP, Kramer HJ, Katz R, Wong ND, Bertoni AG, Carr J, Budoff MJ, Blumenthal RS, Nasir K: Association between coronary artery calcification progression and microalbuminuria: the MESA study. JACC Cardiovasc Imaging 2010;3:595-604.

20 Block GA, Raggi P, Bellasi A, Kooienga L, Spiegel DM: Mortality effect of coronary calcification and phosphate binder choice in incident hemodialysis patients. Kidney Int 2007;71:438-441.

-21 Matsuoka M, Iseki K, Tamashiro M, Fujimoto N, Higa N, Touma T, Takishita S: Impact of high coronary artery calcification score (CACS) on survival in patients on chronic hemodialysis. Clin Exp Nephrol 2004;8:54-58.

22 Bellasi A, Raggi P: Vascular imaging in chronic kidney disease. Curr Opin Nephrol Hypertens 2012;21:382388.

-23 Yoshida H, Yokoyama K, Yaginuma T, Ohkido I, Yamamoto H, Utsunomiya Y, Kawakami M, Hosoya T: Difference in coronary artery intima and media calcification in autopsied patients with chronic kidney disease. Clin Nephrol 2011;75:1-7.

24 Shroff RC, McNair R, Figg N, Skepper JN, Schurgers L, Gupta A, Hiorns M, Donald AE, Deanfield J, Rees L, Shanahan CM: Dialysis accelerates medial vascular calcification in part by triggering smooth muscle cell apoptosis. Circulation 2008;118:1748-1757.

25 Sofi F, Capalbo A, Cesari F, Abbate R, Gensini GF: Physical activity during leisure time and primary prevention of coronary heart disease: an updated meta-analysis of cohort studies. Eur J Cardiovasc Prev Rehabil 2008;15:247-257.

-26 Thompson PD, Buchner D, Pina IL, Balady GJ, Williams MA, Marcus BH, Berra K, Blair SN, Costa F, Franklin B, Fletcher GF, Gordon NF, Pate RR, Rodriguez BL, Yancey AK, Wenger NK: Exercise and physical activity in the prevention and treatment of atherosclerotic cardiovascular disease: a statement from the Council on Clinical Cardiology (Subcommittee on Exercise, Rehabilitation, and Prevention) and the Council on Nutrition, Physical Activity, and Metabolism (Subcommittee on Physical Activity). Circulation 2003;107:3109-3116.

27 Dungey M, Hull KL, Smith AC, Burton JO, Bishop NC: Inflammatory factors and exercise in chronic kidney disease. Int J Endocrinol 2013;2013:569831.

28 Folsom AR, Eckfeldt JH, Weitzman S, Ma J, Chambless LE, Barnes RW, Cram KB, Hutchinson RG: Relation of carotid artery wall thickness to diabetes mellitus, fasting glucose and insulin, body size, and physical activity. Atherosclerosis Risk in Communities (ARIC) Study Investigators. Stroke 1994;25:66-73.

29 Stensland-Bugge E, Bonaa KH, Joakimsen O, Njolstad I: Sex differences in the relationship of risk factors to subclinical carotid atherosclerosis measured 15 years later : the Tromso study. Stroke 2000;31:574-581.

-30 Taylor AJ, Watkins T, Bell D, Carrow J, Bindeman J, Scherr D, Feuerstein I, Wong H, Bhattarai S, Vaitkus M, O'Malley PG: Physical activity and the presence and extent of calcified coronary atherosclerosis. Med Sci Sports Exerc 2002;34:228-233. 


\section{Kidney \\ Blood Pressure Research}

Kidney Blood Press Res 2014;39:154-163

\begin{tabular}{l|l}
\hline DOI: $10.1159 / 000355791$ & (C) 2014 S. Karger AG, Basel
\end{tabular}

Published onine: July 29, 2014

www.karger.com/kbr

Basile et al.: Vascular Calcification and Physical Activity

-31 Kwasniewska M, Jegier A, Kostka T, Dziankowska-Zaborszczyk E, Rebowska E, Kozinska J, Drygas W: Longterm effect of different physical activity levels on subclinical atherosclerosis in middle-aged men: a 25-year prospective study. PloS one 2014;9:e85209.

-32 Desai MY, Nasir K, Rumberger JA, Braunstein JB, Post WS, Budoff MJ, Blumenthal RS: Relation of degree of physical activity to coronary artery calcium score in asymptomatic individuals with multiple metabolic risk factors. Am J Cardiol 2004;94:729-732.

-33 Simprini LA, Villines TC, Rich M, Taylor AJ: The relationship between subclinical atherosclerosis, nonhigh-density lipoprotein cholesterol, exercise, and diet among male participants of the PACC Project. J Clin Lipidol 2012;6:174-179.

-34 Lee CD, Jacobs DR, Jr., Hankinson A, Iribarren C, Sidney S: Cardiorespiratory fitness and coronary artery calcification in young adults: The CARDIA Study. Atherosclerosis 2009;203:263-268.

35 Wilund KR, Tomayko EJ, Evans EM, Kim K, Ishaque MR, Fernhall B: Physical activity, coronary artery calcium, and bone mineral density in elderly men and women: a preliminary investigation. Metabolism 2008;57:584-591.

-36 Sung J, Cho SJ, Choe YH, Choi YH, Hong KP: Prevalence of coronary atherosclerosis in asymptomatic middleage men with high aerobic fitness. Am J Cardiol 2012;109:839-843.

37 Goel R, Majeed F, Vogel R, Corretti MC, Weir M, Mangano C, White C, Plotnick GD, Miller M: Exercise-induced hypertension, endothelial dysfunction, and coronary artery disease in a marathon runner. Am J Cardiol 2007;99:743-744.

38 Mohlenkamp S, Lehmann N, Breuckmann F, Brocker-Preuss M, Nassenstein K, Halle M, Budde T, Mann K, Barkhausen J, Heusch G, Jockel KH, Erbel R: Running: the risk of coronary events : Prevalence and prognostic relevance of coronary atherosclerosis in marathon runners. Eur Heart J 2008;29:1903-1910.

-39 Nassenstein K, Breuckmann F, Lehmann N, Schmermund A, Hunold P, Broecker-Preuss M, Sandner TA, Halle M, Mann K, Jockel KH, Heusch G, Budde T, Erbel R, Barkhausen J, Mohlenkamp S: Left ventricular volumes and mass in marathon runners and their association with cardiovascular risk factors. Int J Cardiovasc Imaging 2009;25:71-79.

-40 O'Keefe JH, Patil HR, Lavie CJ, Magalski A, Vogel RA, McCullough PA: Potential adverse cardiovascular effects from excessive endurance exercise. Mayo Clin Proc 2012;87:587-595.

41 Patil HR, O'Keefe JH, Lavie CJ, Magalski A, Vogel RA, McCullough PA: Cardiovascular damage resulting from chronic excessive endurance exercise. Missouri Med 2012;109:312-321.

42 Bertoni AG, Whitt-Glover MC, Chung H, Le KY, Barr RG, Mahesh M, Jenny NS, Burke GL, Jacobs DR: The association between physical activity and subclinical atherosclerosis: the Multi-Ethnic Study of Atherosclerosis. Am J Epidemiol 2009;169:444-454.

43 Hamer M, Venuraju SM, Lahiri A, Rossi A, Steptoe A: Objectively assessed physical activity, sedentary time, and coronary artery calcification in healthy older adults. Arterioscler Thromb Vasc Biol 2012;32:500-505.

44 von Bonsdorff MB, Groffen DA, Vidal JS, Rantanen T, Jonsson PV, Garcia M, Aspelund T, Eiriksdottir G, Siggeirsdottir K, Launer L, Gudnason V, Harris TB: Coronary artery calcium and physical performance as determinants of mortality in older age: the AGES-Reykjavik Study. Int J Cardiol 2013;168:2094-2099.

-45 Michos ED, Rice KM, Szklo M, Burke GL, Siscovick DS, Tracy RP, Barr RG, Nettleton JA, Greenland P, Jacobs DR, Jr., Post W: Factors associated with low levels of subclinical vascular disease in older adults: multiethnic study of atherosclerosis. Prev Cardiol 2009;12:72-79.

-46 Hamer M, Kivimaki M, Lahiri A, Yerramasu A, Deanfield JE, Marmot MG, Steptoe A: Walking speed and subclinical atherosclerosis in healthy older adults: the Whitehall II study. Heart 2010;96:380-384.

47 Weinberg N, Young A, Hunter CJ, Agrawal N, Mao S, Budoff MJ: Physical activity, hormone replacement therapy, and the presence of coronary calcium in midlife women. Women Health 2012;52:423-436.

48 Storti KL, Pettee Gabriel KK, Underwood DA, Kuller LH, Kriska AM: Physical activity and coronary artery calcification in two cohorts of women representing early and late postmenopause. Menopause 2010;17:1146-1151.

49 Inzitari M, Naydeck BL, Newman AB: Coronary artery calcium and physical function in older adults: the Cardiovascular Health Study. J Gerontol A Biol Sci Med Sci 2008;63:1112-1118.

50 Straub RH, Tanko LB, Christiansen C, Larsen PJ, Jessop DS: Higher physical activity is associated with increased androgens, low interleukin 6 and less aortic calcification in peripheral obese elderly women. J Endocrinol 2008;199:61-68. 


\section{Kidney \\ Blood Pressure Research}

51 Painter P, Roshanravan B: The association of physical activity and physical function with clinical outcomes in adults with chronic kidney disease. Curr Opin Nephrol Hypertens 2013;22:615-623.

52 Faria Rde S, Fernandes N, Lovisi JC, Reboredo Mde M, Marta MS, Pinheiro Bdo V, Bastos MG: Pulmonary function and exercise tolerance are related to disease severity in pre-dialytic patients with chronic kidney disease: a cross-sectional study. BMC Nephrol 2013;14:184.

-53 Reese PP, Cappola AR, Shults J, Townsend RR, Gadegbeku CA, Anderson C, Baker JF, Carlow D, Sulik MJ, Lo JC, Go AS, Ky B, Mariani L, Feldman HI, Leonard MB: Physical performance and frailty in chronic kidney disease. Am J Nephrol 2013;38:307-315.

-54 Mohseni R, Emami Zeydi A, Ilali E, Adib-Hajbaghery M, Makhlough A: The effect of intradialytic aerobic exercise on dialysis efficacy in hemodialysis patients: a randomized controlled trial. Oman Med J 2013;28:345-349.

55 Moe SM, Duan D, Doehle BP, O'Neill KD, Chen NX: Uremia induces the osteoblast differentiation factor Cbfa1 in human blood vessels. Kidney Int 2003;63:1003-1011.

-56 Fabbian F, Manfredini F, Malagoni AM, Malacarne F, Russo G, Soffritti S, Molino C, Catizone L: Exercise training in peripheral vascular arterial disease in hemodialysis patients: a case report and a review. J Nephrol 2006;19:144-149.

57 Mihaescu A, Avram C, Bob F, Gaita D, Schiller O, Schiller A: Benefits of exercise training during hemodialysis sessions: a prospective cohort study. Nephron Clin Pract 2013;124:72-78.

58 Koh KP, Fassett RG, Sharman JE, Coombes JS, Williams AD: Effect of intradialytic versus home-based aerobic exercise training on physical function and vascular parameters in hemodialysis patients: a randomized pilot study. Am J Kidney Dis 2010;55:88-99. 